\title{
Upfront Gamma Knife radiosurgery for Cushing's disease and acromegaly: a multicenter, international study
}

\author{
Amitabh Gupta, MS, MCh, ${ }^{1}$ Zhiyuan Xu, MD, ${ }^{1}$ Hideyuki Kano, MD, PhD, ${ }^{2}$ \\ Nathaniel Sisterson, BA, ${ }^{2}$ Yan-Hua Su, MD, ${ }^{3}$ Michal Krsek, MD, ${ }^{4}$ Ahmed M. Nabeel, MD, PhD, ${ }^{5}$ \\ Amr El-Shehaby, MD, PhD, ${ }^{6}$ Khaled A. Karim, MD, ${ }^{7}$ Nuria Martínez-Moreno, MD, PhD, ${ }^{8}$ \\ David Mathieu, MD, ${ }^{9}$ Brendan J. McShane, BA, ${ }^{10}$ Roberto Martínez-Álvarez, MD, PhD, ${ }^{8}$ \\ Wael A. Reda, MD, PhD, ${ }^{6}$ Roman Liscak, MD, ${ }^{10}$ Cheng-Chia Lee, MD, PhD, ${ }^{3}$ \\ L. Dade Lunsford, MD, PhD, ${ }^{2}$ and Jason P. Sheehan, MD, PhD ${ }^{1}$
}

${ }^{1}$ Department of Neurological Surgery, University of Virginia Health System, Charlottesville, Virginia; ${ }^{2}$ Department of Neurological
Surgery, University of Pittsburgh Medical Center, Pittsburgh, Pennsylvania; ${ }^{3}$ Department of Neurosurgery, Neurological
Institute, Taipei Veterans General Hospital, Taipei, Taiwan, Republic of China; ${ }^{4}$ Second Department of Medicine, Third Faculty
of Medicine of the Charles University, Faculty Hospital Kralovske Vinohrady, Prague, Czech Republic; ${ }^{5}$ Gamma Knife Center
Cairo-Nasser Institute, Neurosurgery Department, Benha University, Benha, Egypt; ${ }^{6}$ Gamma Knife Center Cairo-Nasser Institute,
Neurosurgery Department, Ain Shams University, Cairo, Egypt; ${ }^{7}$ Gamma Knife Center Cairo-Nasser Institute, Clinical Oncology
Department, Ain Shams University, Cairo, Egypt; ${ }^{8}$ Department of Functional Neurosurgery and Radiosurgery, Ruber International
Hospital, Madrid, Spain; ${ }^{9}$ Division of Neurosurgery, Université de Sherbrooke, Centre de Recherche du CHUS, Sherbrooke,
Québec, Canada; and ${ }^{10}$ Department of Stereotactic and Radiation Neurosurgery, Na Homolce Hospital, Prague, Czech Republic OBJECTIVE Gamma Knife radiosurgery (GKS) is typically used after failed resection in patients with Cushing's disease (CD) and acromegaly. Little is known about the upfront role of GKS for patients with CD and acromegaly. In this study, the authors examine the outcome of upfront GKS for patients with these functioning adenomas.

METHODS An international group of 7 Gamma Knife centers sent pooled data from 46 patients (21 with CD and 25 with acromegaly) undergoing upfront GKS to the coordinating center of the study for analysis. Diagnosis was established on the basis of clinical, endocrine, and radiological studies. All patients were treated on a common radiosurgical platform and longitudinally followed for tumor control, endocrine remission, and hypopituitarism. Patients received a tumor median margin dose of $25 \mathrm{~Gy}$ (range 12-40.0 Gy) at a median isodose of $50 \%$.

RESULTS The median endocrine follow-up was 69.5 months (range 9-246 months). Endocrine remission was achieved in $51 \%$ of the entire cohort, with $28 \%$ remission in acromegaly and $81 \%$ remission for those with CD at the 5 -year interval. Patients with CD achieved remission earlier as compared to those with acromegaly $(p=0.0005)$. In patients post-GKS, the pituitary adenoma remained stable (39\%) or reduced (61\%) in size. Hypopituitarism occurred in 9 patients (19.6\%), and 1 (2.2\%) developed third cranial nerve (CN III) palsy. Eight patients needed further intervention, including repeat GKS in 6 and transsphenoidal surgery in 2.

CONCLUSIONS Upfront GKS resulted in good tumor control as well as a low rate of adverse radiation effects in the whole group. Patients with CD achieved a faster and far better remission rate after upfront GKS in comparison to patients with acromegaly. GKS can be considered as an upfront treatment in carefully selected patients with CD who are unwilling or unable to undergo resection, but it has a more limited role in acromegaly.

https://thejns.org/doi/abs/10.3171/2018.3.JNS18110

KEYWORDS Cushing's disease; acromegaly; Gamma Knife radiosurgery; stereotactic radiosurgery

$\mathrm{E}$ XCESSIVE secretion of pituitary hormones, such as adrenocorticotropic hormone (ACTH) in Cushing's disease (CD) and growth hormone (GH) causing acromegaly, may lead to serious endocrine complications if left untreated. Both are associated with significant systemic sequelae and an increased susceptibility to other medical conditions. These sequelae include increased mortality from cardiovascular and cerebrovascular disease, as well as increased morbidity from diabetes mellitus, hypertension, and psychological disturbances..$^{2,9,13,30,40}$ Moreover, if

ABBREVIATIONS ACTH = adrenocorticotropic hormone; $\mathrm{CD}=$ Cushing's disease; $\mathrm{CN}=$ cranial nerve; $\mathrm{CS}=$ cavernous sinus; $\mathrm{GH}=$ growth hormone; $\mathrm{GKS}=\mathrm{Gamma}$ Knife radiosurgery; IGF-I = insulin-like growth factor-I; SRS = stereotactic radiosurgery; UFC = urinary free cortisol.

SUBMITTED January 12, 2018. ACCEPTED March 21, 2018.

INCLUDE WHEN CITING Published online August 17, 2018; DOI: 10.3171/2018.3.JNS18110. 
left untreated, the causative adenoma may increase in size and cause mass effect within the sellar/suprasellar/parasellar space, with symptoms ranging from headaches to visual disturbance, and ultimately may lead to death from hydrocephalus. ${ }^{41}$

For the majority of patients with CD and acromegaly, tumor resection remains the mainstay of treatment, and remission rates after initial resection vary from $50 \%$ to $90 \% .{ }^{15,26-28}$ Remission rates for CD patients with macroadenomas or invasive microadenomas are much lower. ${ }^{15}$ Extirpation of the adenoma conveys risks including damage to optic apparatus and cranial nerves traversing the cavernous sinus (CS), carotid artery injury, CSF leakage, and the development of hypopituitarism..$^{25,29}$

Although in most patients resection of adenoma remains the primary treatment modality, stereotactic radiosurgery (SRS) offers both safe and effective treatment for recurrent or residual pituitary adenomas. In carefully selected instances, radiosurgery may be used for managing patients with pituitary adenomas in whom resection would entail a high level of risk, and for those refusing resection. ${ }^{14}$ In the recent decades, few publications have described the results of primary or upfront Gamma Knife radiosurgery (GKS) for secretory adenomas. ${ }^{6,17,20,24,34}$

In this study we examine the effects of initial or upfront GKS for patients with CD and acromegaly whose records were obtained from an international group of 7 treatment centers, each with a large radiosurgical experience.

\section{Methods}

With institutional review board approval, an international group of 7 Gamma Knife centers retrospectively reviewed the medical records of patients they had treated upfront for CD or acromegaly. A common spreadsheet with specific variables was established and used by all participating centers to collect pertinent patient data, including their demographic information. Finally, the pooled data from 46 patients ( 21 with CD and 25 with acromegaly) undergoing upfront GKS was sent to the coordinating center of study for analysis. In this retrospective study, we defined initial or upfront GKS as the primary mode of treatment given to all patients with CD or acromegaly after the failure of medical management only. Prior to GKS, none of the patients had undergone surgery (for the pituitary or adrenal glands) or received any form of radiation therapy. The reason for taking the patients directly for upfront GKS was either 1) high surgical risk in view of extensive comorbid medical conditions (in 27 patients) or 2) the patient's choice of treatment (in 19).

\section{Study Inclusion Criteria and Patient Cohort}

For inclusion in the study, all patients had the following: 1) clearly demonstrated preoperative laboratory evaluation within 2 months of GKS with findings consistent with CD, including elevated serum cortisol, ACTH, and 24-hour urinary free cortisol (UFC) levels - or for acromegaly, elevated GH and insulin-like growth factor-I (IGF-I) levels; 2) MRI findings consistent with a pituitary adenoma, as interpreted by the treating clinicians and a radiologist; and 3) one or more of clinical, endocrine, and neuroimaging follow-ups.
Of a total of 649 patients with CD or acromegaly who were treated using GKS between 1988 and 2017, 46 patients met the inclusion criteria. The Prague group contributed 15 patients $(32.6 \%)$, Cairo and Spain 7 patients each $(30.4 \%)$, Pittsburgh 8 patients $(17.4 \%)$, Taipei 6 patients (13.1\%), Virginia 2 patients (4.3\%), and Quebec a single patient $(2.2 \%)$.

\section{Clinical and Radiographic Evaluations}

Each patient underwent GKS only after confirming a diagnosis of CD or acromegaly on the basis of clinical, imaging, and hormonal profile. Visual function was assessed as per institutional practices, and any deficits were noted. Endocrine studies typically included baseline measurements of GH, IGF-I, ACTH, cortisol, 24-hour UFC, prolactin, triiodothyronine (T3), thyroxine (T4), free T4, thyrotropin-stimulating hormone, luteinizing hormone, follicle-stimulating hormone, and either estrogen (as well as menstrual history) in females or testosterone in males. Endocrine deficiencies prior to GKS, including hypothyroidism, diabetes insipidus, GH deficiency, and hypogonadism, were defined as either those levels requiring replacement or low values relative to the normal ranges at that site. Radiosurgical planning studies consisted of thinslice stereotactic brain MRI with and without contrast. Tumor volumes were measured using the diameter of tumor in all 3 cardinal planes divided by $2,{ }^{10}$ a third-party tumor volumetric imaging software, ${ }^{37}$ or GammaPlan at the time of radiosurgery and follow-up. ${ }^{31}$ Documentation was made of whether the adenoma was located in the CS or had a suprasellar component.

After GKS, all patients underwent clinical, radiological, and endocrine evaluations, mostly at 6-month intervals for the first 2 years, and then every 1-2 years thereafter. Clinical follow-up information included subsequent treatment with radiosurgery, radiotherapy, or pituitary/adrenal gland surgery; time to endocrine remission; and remission status at last follow-up. The time to remission was defined as the duration from date of GKS to normalization of endocrine values for patients with CD (normal UFC and morning serum cortisol levels) and for those with acromegaly (normal $\mathrm{GH}$ level $<1 \mathrm{ng} / \mathrm{ml}$ in response to a glucose challenge, and a normal serum level of IGF-I when matched for patient age and sex) when off suppressive medications. Hypopituitarism related to radiosurgery was defined as any new hormonal deficit following GKS.

On the follow-up neuroimaging studies an adenoma progression was defined as an increase of at least $20 \%$ in tumor volume, whereas an adenoma regression was defined as at least a $20 \%$ decrease in tumor volume. A tumor size that was within $\pm 20 \%$ of its original volume was defined as stable. No change or a reduction in tumor volume was defined as tumor control. The median endocrine follow-up for patients undergoing upfront GKS was 69.5 months (range 9-246 months).

\section{Gamma Knife Radiosurgery Technique}

All patients underwent stereotactic frame placement after the application of a local anesthetic, supplemented with conscious sedation as needed. Afterward, all patients un- 
TABLE 1. Characteristics of 46 patients who underwent GKS as primary treatment for functioning adenomas: acromegaly and CD

\begin{tabular}{lccc}
\hline & & Value & \\
\cline { 2 - 4 } \multicolumn{1}{c}{ Patient Characteristic } & CD & Acromegaly & Total \\
\hline Median age in yrs (range) & $39(14-79)$ & $58(27-81)$ & $50(14-81)$ \\
\hline Sex (F/M) & $19: 2$ & $15: 10$ & $34: 12$ \\
\hline Median tumor vol in cm ${ }^{3}$ (range) & $0.5(0.01-1.7)$ & $1.1(0.06-7.8)$ & $0.8(0.01-7.8)$ \\
\hline No. of macroadenomas (\%) & $4(19)$ & $14(56)$ & $18(39)$ \\
\hline No. of patients w/ CS extension (\%) & $4(19)$ & $5(20)$ & $9(19.6)$ \\
\hline No. of patients w/ suprasellar extension (\%) & $2(9.5)$ & $1(4)$ & $3(6.5)$ \\
\hline No. of patients w/ pre-GKS hypopituitarism (\%) & $3(14.3)$ & $3(12)$ & $6(13)$ \\
\hline No. of patients w/ pre-GKS visual deficits (\%) & $3(14.3)$ & $3(12)$ & $6(13)$ \\
\hline Median imaging follow-up in mos (range) & $44(3-180)$ & $72(7.2-228.9)$ & $55.7(3-229)$ \\
\hline Median endocrine follow-up in mos (range) & $63(9-246)$ & $87(11.5-235)$ & $69.5(9-246)$ \\
\hline
\end{tabular}

derwent thin-slice stereotactic MRI with and without contrast administration. Radiosurgery was performed using Leksell Gamma Knife Model U, Model 4C, or a Perfexion unit (Elekta Instruments, Inc.), depending on the technology available at that time and site. The radiosurgical parameters investigated were lesion volume or size, number of isocenters, isodose line, maximum radiation dose, and margin dose. Additionally, if a discrete adenoma could not be visualized on stereotactic MRI, the entire sellar contents were included in the treatment volume and this information was recorded. Radiosurgical plans were devised in a multidisciplinary fashion with a neurosurgeon, radiation oncologist, and medical physicist. Critical structure tolerances such as those to the optic apparatus were established locally, but generally followed QUANTEC (Quantitative Analysis of Normal Tissue Effects in the Clinic) and literature-based recommendations..$^{21}$ Radiosurgery was delivered in a single fraction for all patients.

\section{Statistical Analysis}

The data are presented as the median or mean and range for continuous variables, and as frequency in percentages for categorical variables. Statistical analyses were completed using IBM SPSS (version 24). A KaplanMeier method was used to evaluate remission. A binary logistic regression model was used to analyze the prognostic factors of hypopituitarism in the entire cohort of patients. A probability value $<0.05$ was considered statistically significant.

\section{Results}

\section{Patient and Adenoma Characteristics}

The patients' median age was 50 years in the whole cohort, with younger patients (median age 39 years) constituting the $\mathrm{CD}$ subgroup in comparison to the acromegaly (median age 58 years) subgroup (Table 1). Overall, 74\% of the patient cohort were female, constituting the majority for both types of adenoma. Acromegaly accounted for $54.3 \%$ of the upfront cases. The median tumor volume was $0.8 \mathrm{~cm}^{3}$ (range $0.01-7.8 \mathrm{~cm}^{3}$ ) for 46 patients. On the initial MRI study, a macroadenoma (adenoma $>1 \mathrm{~cm}$ in diam- eter) was present in 9 patients $(19.6 \%)$, but the remaining tumors $(80.4 \%)$ were microadenomas. Three patients $(6.5 \%)$ had a suprasellar extension and 9 patients (19.6\%) had some degree of CS extension. The whole sella was treated in $15(33 \%)$ patients, including 7 patients $(33 \%)$ with CD and 8 patients (32\%) with acromegaly.

Before GKS, 6 patients (13\%) had partial pituitary dysfunction with a deficiency in at least one hormonal axis, and 6 patients (13\%) had partial visual field deficits, including 1 with cranial nerve $(\mathrm{CN})$ III paresis before GKS.

\section{Radiosurgical Attributes}

Margin doses varied from 12 to $40 \mathrm{~Gy}$ (median $25 \mathrm{~Gy}$ ) at a median $50 \%$ isodose (range $45 \%-90 \%$ ). The median maximum dose delivered to the optic apparatus was as follows: optic nerve 6.2 Gy (range 1-12 Gy), optic chiasm 5 Gy (range 1-10 Gy), and optic tract 4.5 Gy (range 1-8.5 Gy).

\section{Endocrine Remission}

Endocrine remission was achieved in $51 \%$ of patients in the entire cohort (Fig. 1). Five years post-GKS, the remission rate was $28 \%$ in patients with acromegaly and $81 \%$ in those with CD. This significant difference in remission rates between the 2 subgroups was further analyzed for difference in tumor type, tumor size, margin dose, CS extension or suprasellar extension, and whole sella versus partial sella treatment. The tumor secretory type (i.e., ACTH vs GH) was seen as a significant factor ( $\mathrm{p}=$ 0.0005) in achieving a better remission rate for patients treated with upfront GKS. Hence, the patients with CD fared much better in terms of remission when compared to patients with acromegaly. Also, the median time to remission in the CD group was quicker (12.7 months) after GKS (Fig. 2). Actuarial endocrine remission rates at 1,2, 3 , and 5 years in patients with CD were $46 \%, 68 \%, 74 \%$, and $81 \%$, respectively, and in patients with acromegaly the rates were $4 \%, 8 \%, 17 \%$, and $28 \%$, respectively.

\section{Endocrine Recurrence and Other Management After GKS}

Four patients with acromegaly had an initial remission followed by recurrence, and the median time to recurrence 


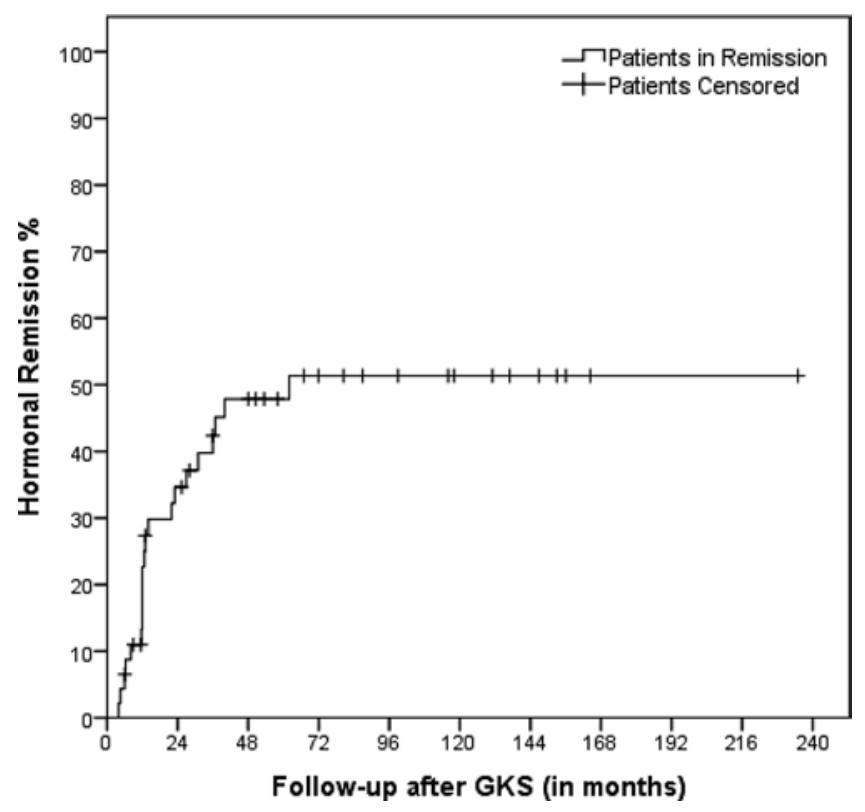

FIG. 1. Kaplan-Meier plot showing that actuarial endocrine remission rates after GKS for the entire study cohort at 1, 2, 3, and 5 years were $23 \%, 35 \%, 42 \%$, and $51 \%$, respectively. The number with follow-up at 1 , 2,3 , and 5 years was $33,27,22$, and 14 patients, respectively.

was 6.8 months (range 2.2-16 months). Five patients who did not achieve durable remission after initial GKS underwent further surgical intervention-repeat GKS in 4 and transsphenoidal resection in 1 . Ten patients required new medical management.

Two patients with $\mathrm{CD}$ had an initial remission followed by recurrence, and the median time to recurrence was 6.2 months (range 6-6.4 months). After GKS for CD, 3 patients not in remission had further surgical interventionrepeat GKS in 2 and transsphenoidal resection in 1. Three patients required new medical management.

\section{Radiological Response}

The tumor volume noted in follow-up was stable in 18 (39\%) and reduced in $28(61 \%)$ of patients. There was no significant difference $(\mathrm{p}=0.5)$ in tumor control rates after upfront GKS for patients with either CD or acromegaly. However, on univariate analysis, inclusion of larger treatment volume for planning of GKS was significantly $(\mathrm{p}=$ 0.043 ) associated with tumor regression on the last followup neuroimaging study.

\section{Postradiosurgical Complications}

The overall outcome of 46 patients with either acromegaly or CD after upfront GKS is summarized in Table 2. Only 1 patient $(2.2 \%)$ demonstrated a $\mathrm{CN}$ deficit following GKS. This patient with CD developed diplopia involving partial oculomotor nerve palsy after the second GKS; his prescription doses to the target volume were $25 \mathrm{~Gy}$ for the first treatment and 20 Gy for the second GKS.

At the last follow-up, new-onset hypopituitarism occurred in 9 patients (19.6\%), including 4 patients with acromegaly and 5 with CD. Five patients had multiple hormon-

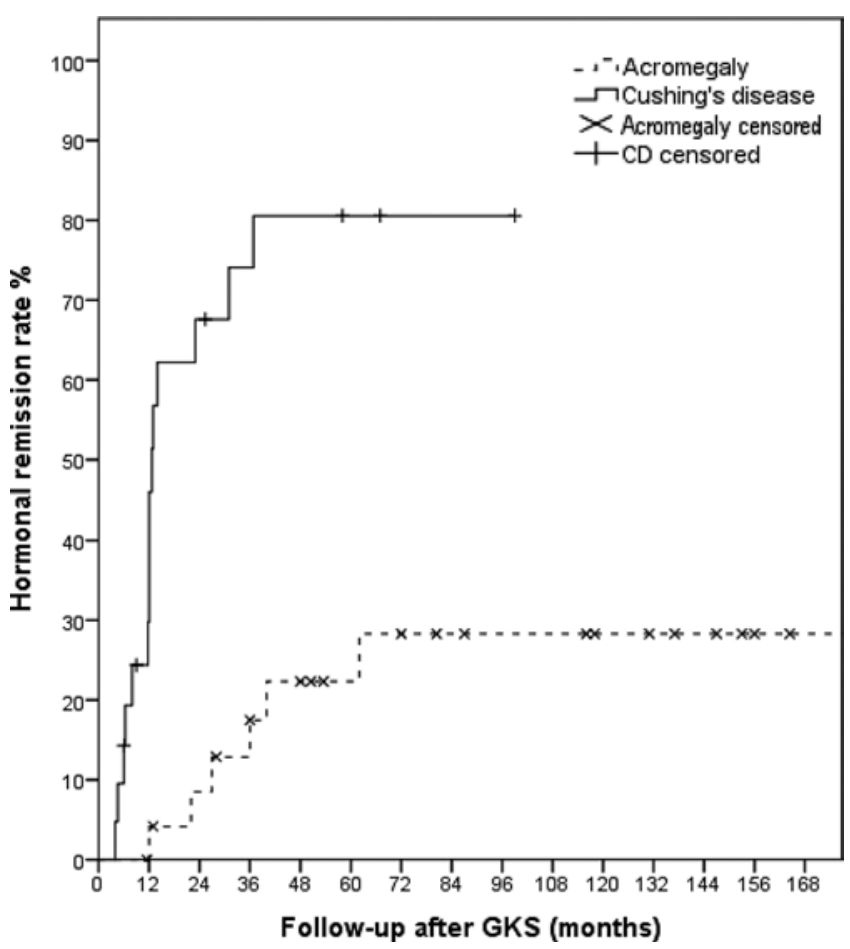

FIG. 2. Kaplan-Meier plot demonstrating differential endocrine remission rates after upfront GKS in patients with adenoma secreting $\mathrm{GH}$ and $\mathrm{CD}$. Patients with CD were more likely to achieve remission $(p=0.0005)$ than those with acromegaly. The number with follow-up at $1,2,3$, and 5 years was 10,6, 4, and 2 patients, respectively, for CD and 25, 21, 17, and 12 patients, respectively, for acromegaly.

al deficiencies, including 2 patients with $\mathrm{CD}$ who developed panhypopituitarism. Thyroid hormone was the most common deficient hormone in combination with other hormonal deficiency, in the following order of frequency: gonadotropin hormone, $\mathrm{GH}$ in patients with $\mathrm{CD}$, ACTH in patients with acromegaly, and diabetes insipidus. After GKS, the median time to develop hypopituitarism was 39 months (6-106 months) and the median margin dose was 30 Gy (range 16-35 Gy). This dose was higher when compared to the median margin dose of 25 Gy (range 12-40 Gy) given to patients without hypopituitarism, but no statistical difference $(p=0.942)$ was seen in an analysis of the margin dose in patients with or without hypopituitarism. None of the patients experienced postradiosurgical stroke, necrosis, or radiation-induced neoplasia.

\section{Discussion}

The main goals in management of secretory pituitary adenomas are tumor control and endocrine normalization. ${ }^{43}$ Surgery seems to achieve this by cytoreduction of the tumor and facilitation of a rapid endocrine response. Hence, in most patients with CD and acromegaly, resection is the treatment of choice. However, complete resection and accompanying endocrine remission cannot always be readily achieved, particularly if the tumor is extending to or invading the CS, clivus, or dura mater. Incomplete surgery rates range from $20 \%$ to $80 \%$ and recurrence rates for pituitary adenomas range from $7 \%$ to $35 \%$, depending 
TABLE 2. Outcome of 46 patients with CD and acromegaly with upfront GKS

\begin{tabular}{|c|c|c|}
\hline Parameter & $\begin{array}{c}\text { No. of } \\
\text { Patients (\%) }\end{array}$ & $\begin{array}{l}\text { Time in Mos } \\
\text { (range) }\end{array}$ \\
\hline \multicolumn{3}{|l|}{ Tumor response } \\
\hline Regression & $28(61)$ & $24(3-60)$ \\
\hline Stability & $18(39)$ & $35.2(3-116)$ \\
\hline Enlargement & 0 & \\
\hline \multicolumn{3}{|l|}{ Clinical improvements } \\
\hline $\begin{array}{l}\text { Discontinued antisecretory } \\
\text { medicine }\end{array}$ & $5(11)$ & \\
\hline $\begin{array}{l}\text { Discontinued hormone } \\
\text { replacement }\end{array}$ & 0 & \\
\hline Started antisecretory medicine & $13(28.3)$ & \\
\hline \multicolumn{3}{|l|}{ Complications } \\
\hline CN II palsy & $0(0)$ & \\
\hline CN III palsy & $1(2.2)$ & \\
\hline Hypopituitarism & $9(19.6)$ & $39(6-106)$ \\
\hline Thyroid deficiency & 4 & \\
\hline Multihormonal deficiency & 3 & \\
\hline Panhypopituitarism & 2 & \\
\hline Cerebrovascular accident & 0 & \\
\hline Radiation necrosis & 0 & \\
\hline $\begin{array}{l}\text { Patients undergoing further } \\
\text { management }\end{array}$ & $\begin{array}{c}8(17.4) ; 2 \\
\text { surgery \& } 6 \\
\text { repeat GKS }\end{array}$ & $\begin{array}{l}\text { GKS at } 39.5 \\
\text { (21-96); surgery } \\
\text { at } 27,48 \text { mos }\end{array}$ \\
\hline
\end{tabular}

on the length of follow-up, tumor size, and adenoma subtype. ${ }^{3,4,8,12,23,39}$ Also, older age and extensive comorbidities may be relative contraindications to a resection. In a recent study, Wilson et al. included 135 patients (81 patients 60-69 years of age and 54 patients 70 years or older) who underwent endonasal endoscopic surgery for pituitary tumor. They noted a complication rate of $7.4 \%$ in patients in the 60 - to 69 -year age group versus $18.5 \%$ in patients older than 70 years (for both overall and cranial complications), and concluded that in elderly patients there was a graded increase in complication rates with increasing age. ${ }^{42}$ In elderly patients with functioning pituitary adenomas or with small to moderate-size adenomas invading the CS, there might be a role for upfront GKS.

GKS is typically used as an adjuvant treatment in patients with persistent $\mathrm{CD}$ and acromegaly after one or more failed surgeries. The post-SRS remission rates reported in the literature vary considerably, from $0 \%$ to $100 \%$, with most series documenting an approximately 50\%-60\% remission rate. . $^{1,11,16,29,32,33,35,38}$ In a previous study published from our group, 41 patients with nonfunctioning pituitary adenoma underwent initial GKS with an overall tumor control rate of $92.7 \%$, and post-GKS hypopituitarism developed in $24 \%$ at a median follow-up of 37 months. ${ }^{18}$

Until recently, little has been studied about the upfront role of GKS for patients with functioning pituitary adenomas, and we found a very limited number of published studies touching on this topic. ${ }^{6,17,20,24,34}$ In one such retrospective study, Castinetti et al. described results in 76 patients with secretory pituitary adenoma, including 49 patients treated postsurgically and 27 treated upfront with GKS. After a mean follow-up of 96 months, $44.7 \%$ of the patients were in endocrine remission, and the mean time to remission was 42.6 months. In the subgroup of 27 patients treated upfront, the mean prescription dose was 28 Gy (range 16-35 Gy), and the mean target volume was 1 $\mathrm{cm}^{3}$ (range $0.132-3.2 \mathrm{~cm}^{3}$ ). These patients had a mean follow-up of 102 months (range 60-144 months), with remission observed in $40.7 \%$ of patients; $50 \%$ of those who had microadenomas were in remission, in contrast to $33.3 \%$ of patients with macroadenomas $(\mathrm{p} \leq 0.05) .{ }^{6} \mathrm{Kim}$ et al. performed a study in 37 patients who had functioning pituitary adenomas comprising $30 \%$ with acromegaly, $22 \%$ with $\mathrm{CD}$, and the rest with prolactinomas. The mean age at GKS was 35.4 years. Twenty-five $(68 \%)$ patients underwent upfront radiosurgery, and the mean maximum dose was 54.8 Gy at a treatment isodose range of 30\%-50\%. Most patients undergoing upfront GKS had microadenomas with a mean tumor volume of $0.9 \mathrm{~cm}^{3}$ (range $0.1-2.6$ $\mathrm{cm}^{3}$ ) and postoperative remission rate of $35.1 \%$ (17\% with prolactinoma, $45.5 \%$ with acromegaly, and $62.5 \%$ with CD) during a mean follow-up of 26.9 months. ${ }^{17}$

The current series demonstrates a statistically significant difference $(p=0.0005)$ with regard to endocrine remission in patients with either CD or acromegaly who were treated upfront with GKS. The actuarial remission rate was $51 \%$, with a rate of $28 \%$ in acromegaly and $81 \%$ in CD. A previous study performed in 136 patients with acromegaly undergoing SRS postresection had a remission rate of $65.4 \%$ at a median follow-up of 61.5 months, ${ }^{19}$ whereas in a similar study in 278 patients with CD the remission rate was $64 \%$ at 10 -year follow-up. ${ }^{22}$ In our study, a significant difference in remission rates between these 2 types of adenomas might be due to the selection bias of patients included from multiple centers. Alternately, this finding could suggest a differential radiosensitivity of functioning pituitary adenomas, which merits further investigation. Nevertheless, with regard to endocrine remission, the role of upfront GKS may be more appealing for $\mathrm{CD}$ than for acromegaly. Most patients suffering with CD have microadenoma, and the value of resection in such cases, particularly if there was evidence of CS invasion by Knosp criteria, may be limited given the efficacy and safety of upfront GKS for CD shown in this series.

Adenoma control is typically achieved after upfront or adjuvant GKS. At the last follow-up, 18 patients (39\%) had a stable tumor size and $28(61 \%)$ showed a reduction in the tumor size, but no significant difference $(\mathrm{p}=0.5)$ was noted in tumor control rates between patients with $\mathrm{CD}$ or acromegaly. However, larger adenomas were more likely $(p=0.043)$ to be associated with adenoma size regression after GKS on univariate analysis. Castinetti et al. reported that adenoma volume remained unchanged in $75 \%$ of their patients after SRS, ${ }^{6}$ and Kim et al. had $67.9 \%$ of volume control overall in their group of patients. ${ }^{17}$

Hypopituitarism remains the most frequent adverse event after radiosurgery for previously resected pituitary adenomas, with the same being true for upfront GKS. We found new hypopituitarism in $19.6 \%$ of patients (4 with acromegaly and 5 with $\mathrm{CD}$ ) after GKS. Three patients with 
CD developed more than 3 different types of hormonal deficiencies, including 2/21 (9.5\%) patients with $\mathrm{CD}$ who developed panhypopituitarism. Castinetti et al. noted at least one new anterior pituitary deficiency after GKS in 16 patients (21\%), including 7 patients treated with upfront GKS. Twelve patients presented with one new anterior pituitary deficiency, including 5 who developed panhypopituitarism. ${ }^{6}$ The patients undergoing GKS postresection had a higher risk (approximately 30\%) ${ }^{44}$ of developing hypopituitarism as compared to our current study. More pristine neuroanatomy in the patients initially treated with GKS, as compared to patients who have had one or more prior resections, may be one of the reasons for lower rates of hypopituitarism in the current study. Postsurgical changes on MRI may make the radiosurgical target as well as critical structure delineation less precise.

New cranial neuropathy was seen in only 1 of our patients $(2.2 \%)$ who had a partial CN III palsy following GKS. Castinetti et al. reported 3 patients with oculomotor impairment, including 2 with transient paralysis of $\mathrm{CN}$ VI. The third patient, who had been previously treated by radiotherapy, presented with a trigeminal neuralgia and a central visual field defect. ${ }^{6}$ In a study by Kim et al., no adverse effect was reported, but this study was limited by a short mean follow-up period of 2 years. ${ }^{17}$

Longitudinal follow-up is needed for patients who underwent upfront GKS for CD and acromegaly. This point is underscored by the current study, in which 6 patients (13\%) had an initial remission after GKS, but later had a recurrence. Endocrine recurrence has been previously described after prior resection, radiosurgery, or radiotherapy. $5,7,14,16,38$

Salvage approaches such as resection, medical management, or repeat radiosurgery may be required for such patients. Three of 6 patients treated with repeat GKS in this study had achieved endocrine remission at the last follow-up. The mean time interval between initial and repeat GKS was 39.5 months (range 21-96 months), and the median dose delivered to the adenoma margin was 23.5 Gy (range 14-35 Gy) in a single fraction. A dose reduction and an interval of at least 1 year between initial and subsequent GKS seems to be prudent for avoiding adverse radiation effects. ${ }^{36}$

\section{Study Limitations}

Although the current study represents the largest series of patients with functioning pituitary adenomas treated by upfront GKS to date, we acknowledge notable limitations to this study. The patient selection bias represents a major limitation of including cases from different centers. At all the participating sites, GKS was typically used as a secondary rather than primary treatment option for patients with CD and acromegaly. Limited longitudinal follow-up in some of the patients may have led to an underestimate of complications and recurrences after initial endocrine remission. The radiosurgical technique and devices varied as a function of time and between centers. Also, variations in the endocrine testing at different centers and a varied approach of the centers regarding withholding suppressive medicines prior to GKS at different points of time may have led to differences in remission and hypopituitarism rates.

\section{Conclusions}

GKS may be considered as an upfront treatment for carefully selected patients who are unwilling or unable to undergo resection for $\mathrm{CD}$, and also, with a more limited role, in patients with acromegaly. Upfront GKS resulted in a reasonable rate of tumor control and a low rate of adverse radiation effects. Patients treated for $\mathrm{CD}$ achieved faster and higher endocrine remission rates compared to patients with acromegaly. Hypopituitarism and endocrine recurrence occurred in a minority of patients, but these factors underscore the importance of longitudinal followup in patients with pituitary adenoma.

\section{Acknowledgments}

We appreciate the assistance of Ms. Linda Baxendell with coordination of data from the International Gamma Knife Research Consortium to the center of study for analysis.

\section{References}

1. Aghi MK, Petit J, Chapman P, Loeffler J, Klibanski A, Biller $\mathrm{BM}$, et al: Management of recurrent and refractory Cushing's disease with reoperation and/or proton beam radiosurgery. Clin Neurosurg 55:141-144, 2008

2. Ayuk J, Sheppard MC: Does acromegaly enhance mortality? Rev Endocr Metab Disord 9:33-39, 2008

3. Blevins LS Jr, Christy JH, Khajavi M, Tindall GT: Outcomes of therapy for Cushing's disease due to adrenocorticotropinsecreting pituitary macroadenomas. J Clin Endocrinol Metab 83:63-67, 1998

4. Buchfelder M, Nistor R, Fahlbusch R, Huk WJ: The accuracy of CT and MR evaluation of the sella turcica for detection of adrenocorticotropic hormone-secreting adenomas in Cushing disease. AJNR Am J Neuroradiol 14:1183-1190, 1993

5. Castinetti F, Nagai M, Dufour H, Kuhn JM, Morange I, Jaquet $\mathrm{P}$, et al: Gamma knife radiosurgery is a successful adjunctive treatment in Cushing's disease. Eur J Endocrinol 156:91-98, 2007

6. Castinetti F, Nagai M, Morange I, Dufour H, Caron P, Chanson $\mathrm{P}$, et al: Long-term results of stereotactic radiosurgery in secretory pituitary adenomas. J Clin Endocrinol Metab 94:3400-3407, 2009

7. Castinetti F, Régis J, Dufour H, Brue T: Role of stereotactic radiosurgery in the management of pituitary adenomas. Nat Rev Endocrinol 6:214-223, 2010

8. Chandler WF, Schteingart DE, Lloyd RV, McKeever PE, Ibarra-Perez G: Surgical treatment of Cushing's disease. J Neurosurg 66:204-212, 1987

9. Colao A, Auriemma RS, Rebora A, Galdiero M, Resmini E, Minuto F, et al: Significant tumour shrinkage after 12 months of lanreotide Autogel-120 mg treatment given first-line in acromegaly. Clin Endocrinol (Oxf) 71:237-245, 2009

10. Davies BM, Carr E, Soh C, Gnanalingham KK: Assessing size of pituitary adenomas: a comparison of qualitative and quantitative methods on MR. Acta Neurochir (Wien) 158:677-683, 2016

11. Devin JK, Allen GS, Cmelak AJ, Duggan DM, Blevins LS: The efficacy of linear accelerator radiosurgery in the management of patients with Cushing's disease. Stereotact Funct Neurosurg 82:254-262, 2004

12. Friedman RB, Oldfield EH, Nieman LK, Chrousos GP, Doppman JL, Cutler GB Jr, et al: Repeat transsphenoidal surgery for Cushing's disease. J Neurosurg 71:520-527, 1989

13. Giustina A, Bronstein MD, Casanueva FF, Chanson P, Ghigo E, Ho KK, et al: Current management practices for acromegaly: an international survey. Pituitary 14:125-133, 2011 
14. Grant RA, Whicker M, Lleva R, Knisely JP, Inzucchi SE, Chiang VL: Efficacy and safety of higher dose stereotactic radiosurgery for functional pituitary adenomas: a preliminary report. World Neurosurg 82:195-201, 2014

15. Hammer GD, Tyrrell JB, Lamborn KR, Applebury CB, Hannegan ET, Bell S, et al: Transsphenoidal microsurgery for Cushing's disease: initial outcome and long-term results. J Clin Endocrinol Metab 89:6348-6357, 2004

16. Jagannathan J, Sheehan JP, Pouratian N, Laws ER, Steiner L, Vance ML: Gamma Knife surgery for Cushing's disease. J Neurosurg 106:980-987, 2007

17. Kim SH, Huh R, Chang JW, Park YG, Chung SS: Gamma Knife radiosurgery for functioning pituitary adenomas. Stereotact Funct Neurosurg 72 (Suppl 1):101-110, 1999

18. Lee CC, Kano H, Yang HC, Xu Z, Yen CP, Chung WY, et al: Initial Gamma Knife radiosurgery for nonfunctioning pituitary adenomas. J Neurosurg 120:647-654, 2014

19. Lee CC, Vance ML, Xu Z, Yen CP, Schlesinger D, Dodson B, et al: Stereotactic radiosurgery for acromegaly. J Clin Endocrinol Metab 99:1273-1281, 2014

20. Marek J, Ježková J, Hána V, Kršek M, Liščák R, Vladyka V, et al: Gamma knife radiosurgery for Cushing's disease and Nelson's syndrome. Pituitary 18:376-384, 2015

21. Mayo C, Martel MK, Marks LB, Flickinger J, Nam J, Kirkpatrick J: Radiation dose-volume effects of optic nerves and chiasm. Int J Radiat Oncol Biol Phys 76 (3 Suppl):S28S35, 2010

22. Mehta GU, Ding D, Patibandla MR, Kano H, Sisterson N, $\mathrm{Su} \mathrm{YH}$, et al: Stereotactic radiosurgery for Cushing disease: results of an international, multicenter study. J Clin Endocrinol Metab 102:4284-4291, 2017

23. Nakane T, Kuwayama A, Watanabe M, Takahashi T, Kato T, Ichihara $\mathrm{K}$, et al: Long term results of transsphenoidal adenomectomy in patients with Cushing's disease. Neurosurgery 21:218-222, 1987

24. Park YG, Chang JW, Kim EY, Chung SS: Gamma knife surgery in pituitary microadenomas. Yonsei Med J 37:165-173, 1996

25. Patil CG, Lad SP, Harsh GR, Laws ER Jr, Boakye M: National trends, complications, and outcomes following transsphenoidal surgery for Cushing's disease from 1993 to 2002. Neurosurg Focus 23(3):E7, 2007

26. Patil CG, Prevedello DM, Lad SP, Vance ML, Thorner MO, Katznelson L, et al: Late recurrences of Cushing's disease after initial successful transsphenoidal surgery. J Clin Endocrinol Metab 93:358-362, 2008

27. Patil CG, Veeravagu A, Prevedello DM, Katznelson L, Vance ML, Laws ER Jr: Outcomes after repeat transsphenoidal surgery for recurrent Cushing's disease. Neurosurgery 63:266271, 2008

28. Prevedello DM, Pouratian N, Sherman J, Jane JA Jr, Vance ML, Lopes MB, et al: Management of Cushing's disease: outcome in patients with microadenoma detected on pituitary magnetic resonance imaging. J Neurosurg 109:751-759, 2008

29. Ram Z, Nieman LK, Cutler GB Jr, Chrousos GP, Doppman JL, Oldfield EH: Early repeat surgery for persistent Cushing's disease. J Neurosurg 80:37-45, 1994

30. Renehan AG, O'Connell J, O'Halloran D, Shanahan F, Potten CS, O'Dwyer ST, et al: Acromegaly and colorectal cancer: a comprehensive review of epidemiology, biological mechanisms, and clinical implications. Horm Metab Res 35:712725,2003

31. Schlesinger D, Snell J, Sheehan J: Shielding strategies for Gamma Knife surgery of pituitary adenomas. J Neurosurg 105 (Suppl):241-248, 2006

32. Seo Y, Fukuoka S, Takanashi M, Sasaki T, Suematsu K, Nakamura J: Gamma knife surgery for Cushing's disease. Surg Neurol 43:170-176, 1995
33. Sheehan JM, Vance ML, Sheehan JP, Ellegala DB, Laws ER Jr: Radiosurgery for Cushing's disease after failed transsphenoidal surgery. J Neurosurg 93:738-742, 2000

34. Sheehan JP, Niranjan A, Sheehan JM, Jane JA Jr, Laws ER, Kondziolka D, et al: Stereotactic radiosurgery for pituitary adenomas: an intermediate review of its safety, efficacy, and role in the neurosurgical treatment armamentarium. J Neurosurg 102:678-691, 2005

35. Sheehan JP, Xu Z, Lobo MJ: External beam radiation therapy and stereotactic radiosurgery for pituitary adenomas. Neurosurg Clin N Am 23:571-586, 2012

36. Sheehan JP, Xu Z, Salvetti DJ, Schmitt PJ, Vance ML: Results of gamma knife surgery for Cushing's disease. J Neurosurg 119:1486-1492, 2013

37. Snell JW, Sheehan J, Stroila M, Steiner L: Assessment of imaging studies used with radiosurgery: a volumetric algorithm and an estimation of its error. Technical note. J Neurosurg 104:157-162, 2006

38. Starke RM, Williams BJ, Vance ML, Sheehan JP: Radiation therapy and stereotactic radiosurgery for the treatment of Cushing's disease: an evidence-based review. Curr Opin Endocrinol Diabetes Obes 17:356-364, 2010

39. Symon L, Logue V, Mohanty S: Recurrence of pituitary adenomas after transcranial operation. J Neurol Neurosurg Psychiatry 45:780-785, 1982

40. Tinnel BA, Henderson MA, Witt TC, Fakiris AJ, Worth RM, Des Rosiers PM, et al: Endocrine response after gamma knife-based stereotactic radiosurgery for secretory pituitary adenoma. Stereotact Funct Neurosurg 86:292-296, 2008

41. Wilson PJ, De-Loyde KJ, Williams JR, Smee RI: Acromegaly: a single centre's experience of stereotactic radiosurgery and radiotherapy for growth hormone secreting pituitary tumours with the linear accelerator. J Clin Neurosci 20:15061513,2013

42. Wilson PJ, Omay SB, Kacker A, Anand VK, Schwartz TH: Endonasal endoscopic pituitary surgery in the elderly. J Neurosurg 128:429-436, 2018

43. Witt TC: Stereotactic radiosurgery for pituitary tumors. Neurosurg Focus 14(5):e10, 2003

44. Xu Z, Lee Vance M, Schlesinger D, Sheehan JP: Hypopituitarism after stereotactic radiosurgery for pituitary adenomas. Neurosurgery 72:630-637, 636-637, 2013

\section{Disclosures}

Dr. Lunsford reports stock ownership in Elekta AB. He is also on the Data and Safety Monitoring Board for Insightec.

\section{Author Contributions}

Conception and design: Sheehan, Gupta. Acquisition of data: Sheehan, Gupta, Kano, Sisterson, Su, Krsek, Nabeel, El-Shehaby, Karim, Martínez-Moreno, Mathieu, McShane, Martínez-Álvarez, Reda, Liscak, Lee, Lunsford. Analysis and interpretation of data: Gupta, Xu. Drafting the article: Gupta. Critically revising the article: Sheehan, Xu, Kano, Lee. Reviewed submitted version of manuscript: Sheehan, Xu, Kano, Sisterson, Su, Krsek, Nabeel, ElShehaby, Karim, Martínez-Moreno, Mathieu, McShane, MartínezÁlvarez, Reda, Liscak, Lee, Lunsford. Approved the final version of the manuscript on behalf of all authors: Sheehan. Statistical analysis: Gupta, Xu. Administrative/technical/material support: Sheehan. Study supervision: Sheehan.

\section{Correspondence}

Jason P. Sheehan: University of Virginia Health System, Charlottesville,VA.jsheehan@virginia.edu. 